ORIGINAL ARTICLE

\title{
Critical Media Effects Framework: Bridging Critical Cultural Communication and Media Effects through Power, Intersectionality, Context, and Agency
}

\author{
Srividya Ramasubramanian (D) ${ }^{1}$ \& Omotayo O. Banjo ${ }^{2}$ \\ 1 Department of Communication, Texas A\&M University, College Station, TX, USA \\ 2 Department of Communication, University of Cincinnati, Cincinnati, $\mathrm{OH}$, USA
}

\begin{abstract}
In this essay, we advance the Critical Media Effects (CME) framework as a way of bridging two major subfields of communication that seldom speak to one another: media effects scholarship and critical cultural communication. Critical Media Effects is situated within the dominant mode of social scientific theorizing within media effects scholarship and draws on four key interrelated concepts from critical cultural communication: power, intersectionality, context, and agency. Critical Media Effects advocates for greater reflexivity, rigor, and nuance in theorizing about media effects to better respond to the complexity and dynamicity of emerging global sociopolitical mediated contexts. Recommendations, salient examples, and future directions for cocreating a shared research roadmap for CME are discussed. Through this work of bridging, we hope to promote more collaborative partnerships, productive engagement, and mutual solidarity across these two important subfields to address the most pressing social issues and challenges of the world today.
\end{abstract}

Keywords: Media Effects, Critical Cultural Communication, Social Justice, Intersectionality, Inclusion

doi: $10.1093 /$ joc/jqaa014

For about 50 years, tensions between critical cultural and social psychological approaches to studying the relationship between media and audiences has persisted, and in some cases has fueled volatile debates between scholars of these two different paradigms (Fink \& Gantz, 1996, Morgan, 2007; Splichal \& Mance, 2018). As critical social scientists who are trained in the media effects tradition and who study identity-related questions, we have found ourselves often caught up in methodological polarization and theoretical divides about ontological and epistemological

Corresponding author: Srividya Ramasubramanian; e-mail: srivi@tamu.edu 
differences that do not completely speak to our lived experiences. The multi-device, multi-platform, multiple-media environment that many media users inhabit today as digital natives means that basic conceptual definitions such as media, audience, and effects are in flux. Within the context of the evolving COVID-19 pandemic, social inequalities, rising populist fascist rhetoric, climate change emergency, rampant misinformation, and vitriolic online environments, it is important to interrogate how communication scholarship continues to stay relevant. As media landscapes become more dynamic, audiences become more complex, and sociopolitical contexts evolve rapidly, we advocate for media effects research to take a multiperspectival approach to effectively address the most pressing research issues of today by drawing from subfields such as critical cultural communication.

Critical cultural communication and media effects scholarship are not necessarily opposing concepts and frameworks; each approach just answers different questions. Critical cultural approaches to media interrogate questions related to systemic power in media ownership, representations, and audience reception. Media effects scholarship typically uses quantitative methods to investigate the nature of media content and its impact on individual attitudes and behaviors as well as intergroup relationships. While media effects scholarship emphasizes issues such as objectivity, categorization, and generalizability, critical cultural communication focuses more on issues of power, positionality, and systemic inequalities. As Splichal and Mance (2018) state, "While critical theory and positivism are definitely opposed conceptual frameworks, critical theory and empirical research per se are not. One can combine them rather than endorse one of them against the other" (p. 233). The current silences, siloed thinking, and serious gaps between these subfields are detrimental to meaningfully theorizing about the new media environments, new generation of media prosumers, and new set of emerging sociopolitical challenges today. It is important for media effects theorizing to go beyond the individual to also consider how structural, institutional, and societal influences shape media experiences. Similarly, critical communication scholars could benefit from empirical, evidence-based support to help nuance theoretical mechanisms.

Almost a decade ago, Meyrowitz (2008) argued for combining critical/cultural studies and medium theory to provide a more holistic view of how media consumers interact with the media. Other scholars have used the term quantitative criticalists to describe scholars who use quantitative data to shed light on the structures and factors that lead to inequalities and injustices (McLaren, 2017; Stage \& Wells, 2014). Additionally, they might "also question measures and analytic practices used in quantitative research, to ensure that they adequately represent circumstances and contexts, and do not themselves inadvertently perpetuate exclusion and hierarchy" (McLaren, 2017, p. 391). Emerging areas such as data activism and critical big data studies are examples of how empirical research could be connected with social justice in meaningful ways (Milan \& van der Velden, 2016). Some examples are Data 4 Black Lives, a collective of social scientists and critical scholars that uses data sciences to bring measurable positive outcomes for Black people and the Resource Center 
for Minority Data at the University of Michigan that codesigns studies with communities of color.

The purpose of this article is to create the much-needed space to open up important dialogs between these two subfields to ask socially relevant research questions relating to media impacts and use multiple approaches to address them at the individual, intergroup, organizational, community, and global levels. Beyond a generic call for greater cross-area partnerships, we propose a Critical Media Effects (CME) framework as a starting point for co-creating a research roadmap for facilitating this bridging in meaningful and effective ways.

\section{The Case for Critical Media Effects}

The word "critical" means: (a) consisting of criticism, (b) exercising or involving careful judgment or judicious evaluation of, (c) relating to, or being a turning point or specially important juncture, (d) indispensable, vital, and (e) of sufficient size to sustain a chain reaction. In this essay, we use "critical" to imply all these meanings in advocating for a CME perspective: as a critique of existing literature, to bring attention to an urgent imperative for a critical turn in media effects research, and with the hope of starting a ripple effect.

Although working class women of color possibly form the majority of the world's population, much of communication scholarship has been conducted within Western, Educated, Industrialized, Rich, and Democratic (WEIRD) nations (Afifi \& Cornejo, in press; Alper, Katz, \& Clark, 2016; Henrich, Heine, \& Norenzayan, 2010). The popular theories, canonical texts, and mainstream journal publications within media effects scholarship have historically been developed and framed within white U.S.-centric ableist heteronormative male contexts without interrogating how these choices might limit theorizing. What is considered normal within media effects scholarship could be a skewed version of reality based on limited samples and the researchers' own worldviews. By excluding non-Western or non-white perspectives, media effects scholars assume Eurocentric views as universal (which violates a significant tenet of theory building), dismiss the culturally distinctive experience of other audience members, and inadvertently participate in a form of symbolic annihilation. Even when there are attempts to go beyond the United States, media imperialism and Eurocentrism are often reinforced by centering scholarship from dominant groups in Western European nations with long histories of colonization in the Global South and discriminatory policies against minoritized groups.

Research on media effects scholarship is often examined at the individual level. In fact, media effects scholarship is often equated with media psychology today, which leads to an emphasis on the individual psyche while largely neglecting social, cultural, political, economic and other macro factors that shape media effects. Although the notion that media can have uniform, direct, and powerful effects on all viewers has largely been rejected, research on conditional media effects have 
focused on individual-level differences based on biological, psychological, and personality factors such as sensation-seeking, arousal, need for cognition, perspective taking, authoritarianism, and moral dispositions (Oliver, 2002). Although there is certainly merit to individual differences, media effects scholarship ought to contend with systemic, structural, and institutional inequalities, which play a role in shaping media outcomes.

Even when theories such as agenda setting, social cognitive theory, and social identity theory go beyond individual differences to include intergroup relations, they do not engage with these concepts from a critical cultural perspective by considering structural hierarchies. For instance, we note that intergroup processes within media effects scholarship often simply designate groups as "ingroups" and “outgroups" without explicitly acknowledging power relations between majorityminority groups. For example, Social Identity Theory (SIT) (Tajfel \& Turner, 1979), a popular theory to study intergroup relations, posits that people, motivated to see themselves positively, evaluate themselves and the groups to which they belong more favorably than socially distant ones or out-groups. However, it does not adequately account for the role that hierarchical structure plays in motivations for an individual's need to belong and thus neglects the degree to which individuals' social location within a social system shapes media experience. Self-Categorization Theory comes close to addressing individuals as members of a social system but its emphasis is largely on cognitive grouping of identities and the circumstantial salience which prime different aspects of the social self (Turner \& Reynolds, 2011).

Another concern within traditional media effects scholarship is that media patterns among majority groups are assumed to be normative and those of minoritized groups are narrowly defined as negative, abnormal, problematic, and even pathological. For instance, it is common for media content, use, and outcomes to be defined and framed as negative, violent, or excessive by researchers with little or no involvement with communities that are being studied. This gap between the researcher and the researched shapes how research problems are defined and what solutions are proposed within media effects. Even when positive and pro-social media effects such as elevation, empathy, and inspiration have been examined (Oliver \& Raney, 2011), these effects have been explained within dominant mainstream groups, which leads to the question, "Positive effects for whom?" Given the power differences among minoritized and majority groups, it is crucial, then, that so-called positive media effects are inclusive and take power into consideration by asking "Who gets to feel positive about whom and why?"

Even when media effects scholarship does focus on minoritized media experiences, it does so through mono-categorical theorizing, which refers to using a single identity lens to understand, describe, and explain how identities shape experiences (Collins \& Bilge, 2016; Goff \& Kahn, 2013). Multiple stigmatizations and layered intersectional oppressions are not considered in understanding media outcomes. For instance, within media violence scholarship, which is arguably one of the most well-researched media topics, perpetrator-victim analysis is often limited to using 
gender-only or race-only identities. Intersectional erasures, even if not intentional, can have significant implications for research design, methods, and theorizing.

\section{Critical Media Effects: Intellectual Foundations}

We propose the CME framework to address some of the shortcomings outlined thus far and to facilitate a more nuanced approach to theorizing within media effects scholarship. This framework provides concrete analytical and conceptual tools on how to systematically and intentionally incorporate critical theory into media effects scholarship. It considers the most pressing socially-relevant problems of our times, how to better amplify the voices of those at the margins of society, and how media can serve as a tool for undoing systemic inequalities. It examines, validates, and affirms marginalized perspectives, including non-white, queer, feminist, postcolonial, poor, indigenous, and other minoritized ones.

In conceptualizing CME, we draw on foundational work from critical cultural scholarship, which is informed and influenced by feminist, critical race, queer, Marxist, and postcolonial approaches, to argue that media effects scholarship needs to go beyond traditional modes of theorizing to pay more attention to notions of power and structural inequities. Although communication scholars in other subareas have bridged critical theory with subfields such as health communication (Dutta, 2010, 2018), organizational communication (Mumby, 2013), technology studies (Bakardjieva \& Gehl, 2017), family communication (Soliz \& Phillips, 2018) and interpersonal communication (Afifi \& Cornejo, in press), the value added by this article is creating a framework specific to media effects, which has largely focused on individual-level effects using a post-positivist paradigm. Here we acknowledge the pioneering scholarship on media and identity, which has laid the groundwork for and is foundational for the framework we have proposed (Armstrong, Neuendorf, \& Brentar, 1992; Oliver, 1996).

\section{The Critical Media Effects Framework: Roadmap, Central Pillars, and Salient Examples}

The CME framework applies four interrelated concepts-power, intersectionality, context, and agency - from critical cultural communication to media effects scholarship. These concepts serve as central pillars and support structures upon which the bridging across subfields becomes possible. This is not to say that these are the only key concepts to advance CME scholarship but we believe these are the most crucial and central concepts that should be considered. Power addresses the hierarchical relationships and structural inequalities between dominant groups and subordinated groups that are marginalized, including within media effects scholarship. Intersectionality challenges mono-categorical theorizing within media effects research by acknowledging overlapping and mutually constructed intersectional identities. Context explores the degree to which media effects research accounts for the 
dynamicity of sociocultural political factors which impact the media experiences. And finally, agency accounts for the active role that media users can play in their media use in participatory and counter-hegemonic ways.

Below, we discuss how each pillar relates to CME, highlight salient examples and best practices (from areas such as critical/cultural studies, psychology, sociology, feminist studies, critical race theory, postcolonial studies, critical disability studies, indigenous studies, political economy, and neo-Marxism) as starting points to illustrate, broaden, and build upon existing media effects scholarship. The CME framework provides scholars with a toolkit of shared language, central concepts, and theoretical tools to converse and collaborate together.

\section{Power and Critical Media Effects}

The CME framework considers the ways in which dominant ideological structures frame users, problems, and solutions within traditional media effects. The question of how knowledge, including about media use and effects, is defined, produced, and distributed in myopic ways along asymmetric power relations across groups is the core of examining power within CME. For example, Dutta $(2010,2018)$ has applied the notions of power to critical health communication by taking a culture-centered approach that analyzes structure, agency, and culture in resisting health inequalities. This approach emphasizes solidarity, reflexivity, and praxis. Similarly, the CME approach challenges the erasures of marginalized voices in the formation of research questions, methods, theories, and initiatives related to media.

Interrupting the existing structures of knowledge production within the dominant post-positivist paradigm of media effects scholarship means questioning universalist and essentialist assumptions about media users and their impacts. Critical interrogation of issues of power also allows for the cocreation of knowledge with and by media users, with an emphasis on users' agency and voice. Such theorizing turns the lens back on the assumptions of post-positivism that often ends up unintentionally reinforcing media inequalities rather than explicitly making space for social justice issues and alternative knowledge structures.

CME argues that macrolevel structural institutional dynamics and policies are just as important as microlevel individual behaviors and interpersonal dynamics in understanding the role that power plays when examining media effects. Group membership within a social system does not accurately capture oppressive societal structures which inform an individual's social experience, with implications for their cognitions, attitudes, emotions, and behaviors. For instance, Hitlin, Scott Brown, and Elder (2006) suggest that "development of a sense of racial self-categorization is inherently social and occurs within racially structured, often discriminatory interactions" (p. 1299). For example, in the context of Black women, bell hooks (2003) has argued: "subordinates in relations of power learn experientially that there is a critical gaze, one that looks to document and one that is oppositional" (p. 95).

The ontological assumptions of critical paradigms presuppose that what is structured does not exist in and of itself and is not merely determined by the individual 
but is shaped by systems and infrastructures that maintain status quo (Trepte \& Loy, 2017). For example, Neville, Lilly, Duran, Lee, \& Browne (2000) Colorblind Racial Attitude Scale goes beyond schematic processing of racial categories to incorporate beliefs related to institutional discrimination. Within health psychology, Scheepers and Ellemers (2019) consider historical factors and structural limitations such as medical exploitation of Black people and the practice of redlining and food deserts in analyzing eating habits among various racial groups. Applying this approach to media effects, the CME framework considers the impact of power status of institutionally disenfranchised persons by connecting individual media behaviors with macrolevel systemic inequalities.

Another way in which CME scholarship incorporates power is by examining media effects through the lens of political economy, neo-Marxism and postcolonial critical perspectives (Fuchs \& Mosco, 2015; Jin, 2006; Oh, 2018; Shome \& Hegde, 2002). From the CME perspective, meaning construction and dominant discourses are often shaped by powerful media institutions and members of society who hold class privilege, political capital, and ideological influence (Fuchs \& Mosco, 2015). Disparities in media ownership and workforce are linked to media monopolization, consolidation, and corporatization, which influence media representation, distribution, and reception processes (Castañeda, Fuentes-Bautista, \& Baruch, 2015). CME scholarship takes power structures into consideration at the global, national, and local levels by challenging "prevailing structures of domination [which] shape various discourses of resistance" (Crenshaw, 1991, p. 1243). CME amplifies the voices of communities that are marginalized within mainstream media. For example, scholars have examined media-based collective action strategies to disrupt status quo hierarchies through Arab Spring and \#BlackLivesMatter (Al-Azdee \& Metzgar, 2018; Sturm \& Amer, 2013). Similarly, Wabwire (2013), Pavarala (2003) and Ramasubramanian (2016) have examined the impact of media ownership on rural Kenyan, Indian, and African-American contexts respectively.

\section{Intersectionality and Critical Media Effects}

What intersectionality adds to the CME framework is the insight that factors that shape mediated experiences are coconstituted and are not mutually independent of one another (Collins \& Bilge, 2016; Crenshaw, 1991). Social inequalities and power dynamics intersect such that diverse identities such as race, gender, class, sexual orientation, nationality, citizenship status, religion, and physical/mental abilities shape everyday mediated experiences in complex ways. Intersectionality as a central node of theorizing opens up important investigations about the intertwined, overlapping, and sometimes contradictory ways in which various forms of inequalities influence social hierarchies, which single-axis theorizing does not adequately account for (Bowleg, 2008; Dubrow, 2008; Goff \& Kahn, 2013; Remedios \& Snyder, 2018).

Rather than look at each identity in isolation, the CME framework suggests that research questions, methods, and analyses examine how multiple identities intersect 
in influencing mediated processes and effects (Dubrow, 2008; Else-Quest \& Hyde, 2016). CME recognizes that using a race-only, gender-only, or class-only framework, for instance, only partially advances knowledge and provides an incomplete and inaccurate picture of mediated inequalities that characterize the lives of those who are simultaneously experiencing racism, sexism, class exploitation, patriarchy, homophobia, and other such oppressive systems. This is not to say that various axes of identities are equally salient, weighted equally, or additive in how they influence experiences (Bowleg, 2008; Else-Quest \& Hyde, 2016).

Intersectionality is not merely asking demographic questions, just like feminist social sciences are much more than simply measuring gender or examining gender differences. Rather, intersectionality and critical approaches address various dimensions of experiences such as discrimination, stress, media access, media representation, etc that are informed by multiple identities and power hierarchies. These factors are considered simultaneously, with the emphasis on the "and" and not the "or," in order to account for a more comprehensive understanding of complex systems of multiple oppressions and privileges (Bowleg, 2008; Remedios \& Snyder, 2018). What this means is that for intersectional analyses, beyond the observed data, the media effects scholar also considers the broader structural inequalities and socio-historic context within which the data emerge. For example, Bowleg (2008) examines observed data within sociohistoric contexts by demonstrating how social systems of racism, sexism, and homophobia are mutually constructed in shaping Black lesbians' intersectional economic inequalities.

A few studies have examined multiple identities such as LGB adolescents (Bond, 2018), colorism and gender (Dixon \& Maddox, 2005), Muslim American youth (Saleem \& Ramasubramanian, 2019), low-income families (Behm-Morawitz, Miller, \& Lewallen, 2018), socioeconomic status and race (Taylor-Clark, Koh, \& Viswanath, 2007), race and gender portrayals (Figueroa-Caballero, Mastro, \& Stamps, 2019), and ethnic marginalization of Native Americans (Kopacz \& Lee Lawton, 2011). However, they do not approach it through a critical lens by engaging with intersectionality as a methodological tool or theoretical concept.

Critical social psychologists have started paving the way for incorporating issues of intersectionality into measurement, research design, and data analyses, that could serve as a possible starting point for media effects scholars to build upon (Bowleg, 2008; Dubrow, 2008; Else-Quest \& Hyde, 2016; Goff \& Kahn, 2013; Remedios \& Snyder, 2018). For instance, Garnett et al. (2014) have used Latent Class Analysis (LCA) as an exploratory analytical tool to analyze co-occurring adverse outcomes such as weight-based bullying, homophobia, and racism without disentangling them by specific identity dimensions. Else-Quest and Hyde (2016) provide specific guidelines such as distinguishing framing identities as person variables or as stimulus variables, using within-group designs and between-group comparisons, considering conceptual equivalence and measurement invariance, 
and using techniques such as statistical interactions and multi-level modeling to incorporate intersectionality.

\section{Context and Critical Media Effects}

Much of the traditional media effects scholarship on context relates to examining the effects of specific media genres such as sports, news, humor, or horror. There is a need to go beyond these narrow definitions of context to consider how factors such as social, cultural, political, and technological contexts shape media effects. Medium theorists have argued for a level of analysis that emphasizes the characteristics of a specific medium, suggesting that just as the characteristics of a landscape shape the culture and develop human behavior associated with that region, the features of a particular medium draw a particular audience with specific needs or interests (Meyrowitz, 2008). Morah and Omojola's (2018), for example, examine how technological affordances of social media cultivate entrepreneurial audiences in Nigeria.

Other media effects scholars have done work on user characteristics and contextual factors (Chaffee, 1986; Katz, Blumler, \& Gurevitch, 1973; McGuire, 2004; Valkenburg \& Peter, 2013). For instance, Valkenburg and Peter (2013) have proposed the differential media effects framework, which argues for more nuanced theorizing about differential effects on certain users. Similarly, Lee and Niederdeppe (2011) have contextualized cultivation effects by genre and source of information (overall versus local) on health beliefs. Such studies exemplify the need for nuanced theorizing about context to better incorporate varying needs across communities.

Building on this existing body of work, the CME approach considers environmental boundary constraints such as technological, social, political, and cultural contexts; especially in terms of how they relate to issues of power, and has varying implications for how we frame research questions and outcomes in studying media impacts within various contexts. Social scientific philosophers like Popper (2005) have argued that a goal of scientific inquiry should be to falsify (not prove) a generalizing theory in order to identify the specificity needed to examine complex phenomena. The CME perspective encourages media effects theories to be tested across multiple contexts, content types, formats, and populations, especially emphasizing historically marginalized ones, so that their generalizability, relevance, and applicability can be ascertained.

It is important to consider the social characteristics of users by incorporating the characteristics of the audience which is drawn by or avoids a particular medium. Chiu, Gelfand, Yamagishi, Shteynberg, \& Wan (2010), for example, proposed an intersubjective approach to nonreductionist contemporary theories of psychology that argue that "social behaviors invariably take place in relational contexts and should be understood as responses to socially constructed meanings" (p. 483). The CME approach considers the social and cultural locations of content creators within media effects. It acknowledges that much of entertainment consumption, especially in 
a hyper-digital era, is shared and is a social experience. A few media scholars have incorporated context by studying social characteristics of media use and viewers' responses (Banjo, 2013; Banjo et al., 2017), co-viewers' gendered reactions to sexual violence in film (Tal-Or \& Tsfati, 2015), social connectedness via co-viewing (Haridakis \& Hanson, 2009), and social media context versus a physical viewing context (Cohen \& Lancaster, 2014).

Political contexts shape how media effects researchers formulate research questions, interpret data, and draw conclusions. For example, Rodríguez, Ferron, \& Shamas (2014) account for historical context and the political economy of information in citizens' media. Other scholars study the effects of political context on media directly. Cho (2011), for instance, takes a multi-level approach by examining the effect of local political information on local ad markets exemplifying the impact of community characteristics on political behaviors. Current events and political context can be used throughout all steps of the research process to generate more nuanced results. Scholars have examined representations of sociopolitically relevant groups such as immigrants (Mastro, 2019) or Muslims (Saleem \& Ramasubramanian, 2019) within the broader context of discriminatory public policies against these groups. Others such as Dal Yong Jin (2006), Fuchs and Mosco (2015) and Rodríguez et al. (2014) push scholars to consider broader political economic issues such as media imperialism and neoliberal cultural politics, especially in terms of U.S. and European dominance in media environments, even as they engage with rigorous microlevel studies that test specific hypotheses in controlled settings.

Perhaps the most significant context for our field to consider is that of culture. Edward Said's (1978) important work on Orientalism challenges scholars to consider the imperialistic relationship between the West and the East and its role in how we conduct research. For example, Cho and Han's (2004) research revealed cultural differences in third person effects where greater effects emerged among individualistic samples compared to collectivistic cultures where the distance between self and other is not as great. Kim, Seo, Yu, \& Neuendorf (2014) find a preference for positive affect for U.S. audiences and mixed affect responses among Korean viewers, making room for new ways of theorizing media effects. Their work challenges dominant arguments in favor of trait and affective state motivations for entertainment selection by considering Buddhist inspired beliefs about hedonic pleasure among East Asian audiences. Even within a specific geographical area, subcultures can vary depending on power, status, and positionality. For instance, the cultures of Tamil-Singaporeans, Afro-Latinx Haitians, Romani-Europeans, and indigenous groups in Brazil are significantly distinct from mainstream cultures. Several non-Western media are prime candidates for studies of transportation, empathy and other emotion-oriented, affective and cognitive processing phenomena. For example, films such as Straight Outta Compton can be used to study nostalgia, The Best Man Holiday to examine interpersonal relationships or Crazy Rich Asians to study perceptions of romance or mood regulation. Countries such as India and Nigeria are among the biggest producers of films, those such as China, Japan, and 
Korea have millions of gamers, and nations like Mexico and Brazil have vast networks of television audiences whose perspectives could provide the opportunity to explore culturally relevant effects which have often been overlooked within media effects. These examples highlight the importance of situating media effects in ecologically valid ways that account for the sociocultural political contexts of individuals' media experiences.

\section{Agency and Critical Media Effects}

Building on media effects approaches such as Uses and Gratifications and selective information processing (Katz, Blumler, \& Gurevitch, 1973; McGuire, 2004; Rubin, 2009), CME emphasizes being more user focused by incorporating user agency into theories and applications of media effects. While these approaches define agency in terms of active versus passive audience based on awareness of their relationship to media, the CME approach goes beyond the active-passive binary to emphasize media users' agency to create meaning and counter the hegemonic nature of mainstream dominant media discourses from a critical cultural studies perspective (Couldry, 2004; Hall, 1980). In today's digital convergence culture of prosumption where media users are both cocreators and consumers of content, effects scholarship needs innovative ways of theorizing about user agency, especially including minoritized perspectives, by fully accounting for fandom, pleasure, participatory cultures, engagement, and agentic media use (Couldry, 2004; Jenkins \& Deuze, 2008).

Without taking a technologically optimistic celebratory view of media, CME argues that dominant theorizing within media effects research tends to have focus excessively on harm, risk, and other negative effects, especially in terms of characterizing media use of minoritized groups (Alper et al., 2016, Vickery, 2017). For example, excessive media use, say the use of selfies, is framed as addictive, psychologically harmful, or narcissistic. Similarly, inoculation approaches to media literacy have been critiqued as being too prescriptive in that such interventions are often designed to "save" children from negative effects through positive role modeling without considering user-centered perspectives on media choice, use, and effects (Vickery, 2017).

The CME approach considers the hegemonic notions of what is considered high versus low culture. Media behavior of media users from marginalized groups, in particular, is examined through a deficit-based perspective of social deviance as problems to be "fixed" (Alper et al., 2016). For instance, content such as hip hop has been framed as violent or using "improper" English rather than examining the cultural context within which it emerged as a way of "talking B(l)ack." Similarly, studies of effects of erotic media content, social media consumption, reality TV, and soap operas are often assumed to be "trashy," judged as low culture or assumed to have harmful effects. The CME approach does not take an essentialist view of social differences. Difference is seen as an asset or an opportunity, and not as a problem to be fixed. It challenges what it is "normal" media use and questions if such normality is even desirable, especially if it is defined mainly from the perspective of researchers and from those in authority positions. 
Although recent media effects theories include more positive effects such as inspiration and elevation (Oliver \& Raney, 2011), they do not consider power relations in such theorizing. Ideas from critical disability studies (Goodley, 2013) and critical affect theory (Edbauer Rice, 2008) would readily help scholars recognize that messages about people with disabilities, for instance, overcoming everyday challengesthe supercrip narrative-might be inspirational for able-bodied persons (Bartsch, Oliver, Nitsch, \& Scherr, 2016) but could be insulting to those with disabilities. Indeed, such narratives have been referred to as inspiration porn where stories about exploited groups serve as elevation and inspiration for dominant group members in the context of disabilities ${ }^{1}$ (Grue, 2016), poverty (Beresford, 2016), and racial/ethnic minorities (Apel, 2005). ${ }^{2} \mathrm{CME}$ argues that it is important to carefully examine seemingly positive portrayals such as pity and inspiration in terms of whether or not they reinforce social hierarchies (Ramasubramanian \& Oliver, 2007; Ramasubramanian, Winfield \& Riewestahl, in press).

Centering user agency means approaching research from a space of cultural humility that allows participants the agency to cocreate knowledge and have a more active role in the research process. Inclusive language such as minoritized, enslaved populations, and overly exploited countries put the onus on those exploiting power to oppress other groups (Joseph, 2017). For example, social psychologist Carrotte et al. (2016) made sure to test their survey measures with gender and sexually diverse (GSD) participants to avoid heteronormative language that could be alienating and misrepresent some sexual experiences. Similarly, Broussard, Warner, \& Pope (2017) worked closely with cisgender, transgender, nonbinary participants across a variety of sexual orientations to determine ways to represent gender identity accurately. CME encourages such participatory approaches to defining and measuring concepts.

CME further emphasizes examining marginalized groups within their own cultural contexts without having to compare them with dominant group norms. Only a few studies within media effects have focused on content created by and effects of mainstream media on minoritized communities (e.g., Martinez \& Ramasubramanian, 2015; Saleem \& Ramasubramanian, 2019). CME emphasizes minoritized users' agency to question, challenge, and subvert mainstream media by reframing content, even as mega media corporations continue to create homogenized content within neoliberal capitalist structures. Rodríguez's (2011) work, for example, formulates a theory of how media enable citizens to thrive during political unrest in Colombia and Pavarala (2003) engages with indigenous resistances through community radio.

\section{Charting the Terrain Ahead: Implications and Future Directions}

The CME framework proposed here provides a unifying framework, research toolkit, shared language, and roadmap for bridging critical cultural communication with media effects scholarship. The four central pillars of power, intersectionality, context, and agency that are elaborated upon in this framework can be applied to 
and extended across various mediated contexts. The salient examples, best practices, and recommendations provided here help us imagine the transformative possibilities that such collaborations, cross-area partnerships, and broad applications can offer. Beyond research and theory-building, CME also has implications for pedagogy, curriculum, hiring, promotion, mentoring, leadership and community engagement in terms of whose perspectives and experiences are privileged, how resources are allocated, and how priorities are set in terms of disciplinary directions and institutional support.

CME moves the subfield of media effects into an exciting direction by being responsive to examining, theorizing about, and addressing some of the most pressing social issues, challenges, and questions within Communication today. We envision that the next stage of CME scholarship will explore the full spectrum and range of media effects and experiences, especially minoritized perspectives. Such scholarship goes beyond a narrow focus on individual media outcomes and differences to also incorporate macrolevel questions such as media access, rights, services, representation, and policies for minoritized groups to fully participate and engage in individual and social transformation. It engages with understudied topics such as poverty, social class, racism, homelessness, transphobia, casteism, colorism, and indigeneity across various mediated contexts using critical intersectional lenses. Using an assetbased perspective, it questions implicit assumptions of what is considered "normal" in media effects, as defined from a space of privilege (such as wealth, ablebodiedness, citizenship, whiteness, heteronormativity).

With regard to theoretical implications, the CME framework is not only applicable to studies relating to "other" cultures and to scholarship that is explicitly about identity, social justice, and discrimination. It urges media effects scholars to interrogate claims of the universal applicability, generalizability, and relevance of all media effects theories, concepts, and models. Taking, say, a color-evasive, gender-neutral, and Eurocentric approach to conceptualizing, researching and theorizing about media and its effects is not the solution. Rather, the CME approach encourages applying, studying, and testing media effects theories, including established and popular ones, across subpopulations and cultural contexts to better identify their boundaries, generalizability, robustness, applicability, and falsifiability (Popper, 2005). Replicating studies across diverse samples through intentional recruitment, crossnational collaborations, and community partnerships would increase generalizability of these existing theories. It serves as an invitation for scholars to theorize in new and inclusive ways about all types of media effects across various contexts, users, and texts.

In terms of methodological implications, CME calls to question how key variables such as social categories, identity, and media use are often defined and measured from a dominant group perspective. Practices such as cocreating conceptual definitions and pretesting research instruments with typically neglected groups could address these issues. Partnerships with community-based organizations through long-term mutually beneficial relationships can help with such 
participatory methods. CME research should also be open to incorporating qualitative methods such as media ethnography, examining multiple levels of analysis, and connecting individual media behaviors with structural and systemic factors. The use of multiplicative interactions, contextualization of observed data within larger sociohistorical contexts, and attention to systemic variations across subpopulations are important to consider (Bowleg, 2008, Dubrow, 2008; Else-Quest \& Hyde, 2016).

With respect to inclusive sampling practices, several communication scholars have suggested practical solutions to diversify research samples in terms of geodemographic and social characteristics to capture broader user experiences and media content (Afifi \& Cornejo, in press; Soliz \& Phillips, 2018). Beyond cross-cultural studies, marginalized groups can be studied on their own terms without always having to compare them to dominant group norms. Often small sample sizes and access to minoritized populations are major challenges to overcome. However, collecting data relating to minoritized groups and their experiences are important for them to feel included, respected, and heard. Through methods such as meta-analyses, combining datasets, and longitudinal data, some of the challenges of small samples can be overcome.

The CME approach seeks to bring about structural and institutional changes in media industries and media policies beyond studying individual-level effects. One way to do this is by interrogating taken-for-granted neutrality of the processes through which stories are selected, characters are created, and actors are chosen. For example, Dr. Stacy Smith's Media, Diversity, and Social Change Initiative uses empirical data to influence hiring practices across several entertainment platforms by taking media effects research beyond academe to content creators and media industries, providing opportunities to address issues of inequality in storytelling and production processes (e.g. inclusion contracts).

The CME approach actively supports alternative, community-oriented, and ethnic media initiatives from around the world through research, teaching, and advocacy efforts by working to raise awareness of what stories are being erased and silenced in mainstream media. Collaborations between activists, community leaders, and media effects scholars would strengthen evidence-based, data-driven social scientific approaches to using media for social change in socially relevant, transformative, and meaningful ways. Other examples of such community-based media initiatives are Question Bridge, Latinitas Magazine, Media Rise, Center for Scholars and Storytellers, and citizens' participatory media in India and Columbia discussed earlier (Pavarala, 2003; Ramasubramanian, 2016; Rodríguez et al., 2014). Leadership institutes, mentoring networks, and micro-financing support for alternative media can also help build capacity.

We also need to contend with structural, systemic, and institutional inequalities in conducting and publishing CME scholarship, which need to be addressed in terms of broader access to, allocation, and distribution of resources. This means working intentionally and collaboratively toward a cultural shift in terms of addressing inclusion at many different levels from research agendas to sampling techniques 
to theory testing to community-engaged scholarship to media activism. Doing so requires leaders working together to determine concrete benchmarks and ways to share resources for inclusive CME research, teaching, and community engagement at the disciplinary and institutional levels. Many top journals within Communication are heavily oriented toward publishing media effects research that involves multiple studies, longitudinal surveys, and complex experimental designs. However, such methodologies require resources that might not be available to scholars from marginalized communities, especially outside of the United Studies and Europe. Lab-based experimental research, for instance, involves sophisticated equipment and measurement tools, which are limited to scholars with space and funding support. Gaining access to national samples for surveys, for example, also requires funding, which may not be available to scholars from under-resourced institutions around the world. Access to knowledge in terms of journals, books, media, software, and mentorship could be barriers for scholars from underprivileged backgrounds, especially in the Global South.

Leadership in professional networks and disciplinary organizations could help alleviate these inequalities by facilitating greater collaboration across institutions, nations, and subdivisions by providing seed grants, networking opportunities, and assistance with access to data collection, publications, media texts, research materials, and equipment for those from under-resourced scholarly communities. Disciplinary leaders such as editors could be intentional about collecting author background information, having diverse editorial boards and ad-hoc reviewers, and encouraging citation of literature outside of "canonical" paradigms from nontraditional perspectives (Chakravartty, Kuo, Grubbs, \& McIlwain, 2018). Communication journals and conferences could make inclusion and diversity an explicit part of their research agenda and reviewing criteria, require authors to be more intentional about justifying sampling decisions and find ways to support and reward scholarship that focuses on minoritized groups, media content, and users (Afifi \& Cornejo, in press).

The CME framework also has significant implications for teaching and curriculum development by being purposeful about diversifying who is included in conference panels, special issues of journals, textbooks, class syllabi, bibliographies, and reading lists. Universities and professional organizations need to create mechanisms for better disciplinary and institutional support for hiring, tenure, promotion, and advancement of critical media scholars through developing protocols to understand implicit biases in reviewing and feedback, developing mentoring programs, and providing support for collecting inclusive samples or for collaborating with community-based organizations as part of their research.

While championing a critical approach to studying media impacts, we are not unaware of the limitations that such an approach presents methodologically and practically in terms of research design, methods, sampling, data collection, and data analysis. We have provided some salient examples and recommendations from recent research from areas such as social psychology and health communication to 
start envisioning some ways to address these limitations and challenges. Through conversations and dialogs in our classrooms, at our conferences, and in our communities, and, through special issues of journals, edited books, workshops, blogs, and other outlets, the framework proposed here will be further fine-tuned, fleshed out, and firmed up. The applications, implications, limitations, and scope of the CME framework will unfold through these scholarly spaces in a dialectical manner.

In conclusion, in this article, we bridge media effects scholarship with critical cultural communication by proposing the CME framework and offer four interrelated concepts as the core pillars of this framework: power, intersectionality, context, and agency. In doing so, we hope to facilitate collaborative partnerships, productive engagement, and mutual solidarity between these two subfields. We argue for a more nuanced, intersectional, and critical approach to theorizing media effects scholarship to better reflect the diversity and dynamicity of media experiences, especially in the emerging sociopolitical landscape. We suggest that media effects scholars consider the unmitigated role of power relations, limitations of monocategorical theorizing, and intersectional erasures in how they examine mediated experiences, impacts, and interventions. The framework considers how sociocultural and political factors impact viewers' responses, employs an asset-based approach to understanding marginalized groups' media experiences, and centers participatory, audience-created content, and alternative media. It pays attention to the ways in which dominant hegemonic structures shape media discourses and encourages media effects scholars to incorporate minoritized perspectives in cocreating knowledge, theories, and initiatives.

\section{Notes}

1. Inspiration porn is "the representation of disability as a desirable but undesired characteristic, usually by showing impairment as a visually or symbolically distinct biophysical deficit in one person, a deficit that can and must be overcome through the display of physical prowess" (Grue, 2016, p. 838).

2. Among other scholars who write on this topic, Apel (2005) draws a comparison between lynching postcards that were circulated as souvenirs by white supremacists after lynching murders of Black residents in their neighborhoods with photographs of Abu Ghraib Iraqi prisoners being tortured and humiliated being circulated as spectacles that reinforce hegemonic white American supremacy.

\section{Acknowledgements}

The authors are grateful to Mary Beth Oliver for her encouragement and guidance, to Priya Stephen and Emily Riewestahl for their research assistance, and to David Oh, the special issue editors and three reviewers for their feedback. The authors are grateful to all those on the frontlines of COVID-19, which was declared a global pandemic by WHO two days after this paper was accepted for publication. There are no financial conflicts of interest to disclose. 


\section{References}

Afifi, W. A., \& Cornejo, M. (in press). \#CommunicationsoWEIRD: The question of sample representativeness in interpersonal communication research. In M. L. Doerfel, \& J. L. Gibbs (Eds.), Building inclusiveness in organizations, institutions, and communities: Communication theory perspectives. New York: Routledge.

Alper, M., Katz, V. S., \& Clark, L. S. (2016). Researching children, intersectionality, and diversity in the digital age. Journal of Children and Media, 10(1), 107-114. doi: $10.1080 / 17482798.2015 .1121886$

Al-Azdee, M., \& Metzgar, E. (2018). The Arab spring: Beyond media effects. Journal of Arab \& Muslim Media Research, 11(1), 3-23. doi:10.1386/jammr.11.1.3_1

Apel, D. (2005). Torture culture: Lynching photographs and the images of Abu Ghraib. Art Journal, 64(2), 88-100. DOI: 10.1080/00043249.2005.10791174

Armstrong, G. B., Neuendorf, K. A., \& Brentar, J. E. (1992). TV entertainment, news, and racial perceptions of college students. Journal of Communication, 42, 153-176. doi: 10.1111/j.1460-2466.1992.tb00804.x

Bakardjieva, M., \& Gehl, R. W. (2017). Critical approaches to communication technology the past five years. Annals of the International Communication Association, 41(3-4), 213-219. doi:10.1080/23808985.2017.1374201

Bartsch, A., Oliver, M. B., Nitsch, C., \& Scherr, S. (2016). Inspired by the paralympics: Effects of empathy on audience interest in para-sports and on the destigmatization of persons with disabilities. Communication Research, 45(4), 525-553. doi:10.1177/0093650215626984

Banjo, O. O. (2013). For us only? Examining the effect of viewing context on black audiences' perceived influence of black entertainment. Race and Social Problems, 5(4), 309-322.

Banjo, O. O., Wang, Z., Appiah, O., Brown, C., Walther-Martin, W., Tchernev, J., \& Irwin, M. (2017). Experiencing racial humor with outgroups: A psychophysiological examination of co-viewing effects. Media Psychology, 20(4), 607-631. doi:10.1080/15213269. 2016.1234396

Behm-Morawitz, E., Miller, B. M., \& Lewallen, J. (2018). A model for quantitatively analyzing representations of social class in screen media. Communication Research Reports, 35(3), 210-221. doi:10.1080/08824096.2018.1428544

Beresford, P. (2016). Presenting welfare reform: Poverty porn, telling sad stories or achieving change?. Disability \& Society, 31(3), 421-425. doi : 10.1080/09687599.2016.1173419

Bond, B. (2018). Parasocial relationships with media personae: Why they matter and how they differ among heterosexual, lesbian, gay, and bisexual adolescents. Media Psychology, 21(3), 457-485. doi:10.1080/15213269.2017.1416295

Bowleg, L. (2008). When Black + Lesbian + Woman $\nsucceq$ Black Lesbian Woman: The methodological challenges of qualitative and quantitative intersectionality research. Sex Roles, 59(5-6), 312-325. doi : 10.1007/s11199-008-9400-z

Broussard, K., Warner, R., \& Pope, A. (2017). Too many boxes, or not enough? Preferences for how we ask about gender in cisgender, LGB, and gender-diverse samples. Sex Roles, 78(9), 606-624. doi:10.1007/s11199-017-0823-2.

Carrotte, E. R., Vella, A. M., Bowring, A. L., Douglass, C., Hellard, M. E., Lim, M. S. (2016). "I am yet to encounter any survey that actually reflects my life": A qualitative study of inclusivity in sexual health research. BMC Medical Research Methodology, 16, 86. https://doi. org/10.1186/s12874-016-0193-4 
Castañeda, M., Fuentes-Bautista, M., \& Baruch, F. (2015). Racial and ethnic inclusion in the digital era: Shifting discourses in communications public policy. Journal of Social Issues, 71(1), 139-154. doi:10.1111/josi.12101

Chaffee, S. H. (1986). Mass media and interpersonal channels: competitive, convergent or complimentary? In G. Gumpert \& \& R. Cathcart (Eds.), Intermedia: Interpersonal communication in a media world, 3 (pp. 62-80). New York, NY: Oxford University Press.

Chakravartty, P., Kuo, R., Grubbs, V., \& Mcllwain, C. (2018). \#CommunicationSoWhite. Journal of Communication, 68(2), 254-266. https://doi.org/10.1093/joc/jqy003

Chiu, C. Y., Gelfand, M. J., Yamagishi, T., Shteynberg, G., \& Wan, C. (2010). Intersubjective culture: The role of intersubjective perceptions in cross-cultural research. Perspectives on Psychological Science, 5(4), 482-493. doi:10.1177/1745691610375562.

Cho, H., \& Han, M. (2004). Perceived effect of the mass media on self vs. other: A cross-cultural investigation of the third person effect hypothesis. Journal of Asian Pacific Communication, 14(2), 299-318. doi:10.1075/japc.14.2.06cho

Cho, J. (2011). The geography of political communication: Effects of regional variations in campaign advertising on citizen communication. Human Communication Research, 37(3), 434-462.

Cohen, E. L., \& Lancaster, A. L. (2014). Individual differences in in-person and social media television coviewing: The role of emotional contagion, need to belong, and coviewing orientation. Cyberpsychology, Behavior, and Social Networking, 17(8), 512-518. doi: 10.1089/cyber.2013.0484

Collins, P. H., \& Bilge, S. (2016). Intersectionality. Hoboken, New Jersey: John Wiley \& Sons.

Couldry, N. (2004). Theorising media as practice. Social Semiotics, 14(2), 115-132. doi: $10.1080 / 1035033042000238295$

Crenshaw, K. (1991). Mapping the margins: Intersectionality, identity politics, and violence against women of color. Stanford Law Review, 43(6), 1241-1299.

Dixon, T. L., \& Maddox, K. B. (2005). Skin tone, crime news, and social reality judgments: Priming the stereotype of the dark and dangerous Black criminal. Journal of Applied Social Psychology, 35(8), 1555-1570. doi:10.1111/j.1559-1816.2005.tb02184.x

Dutta, M. J. (2010). The critical cultural turn in health communication: Reflexivity, solidarity, and praxis. Health Communication, 25, 534-539. doi:10.1080/10410236.2010.497995

Dutta, M. J. (2018). Culture-centered approach in addressing health disparities: Communication infrastructures for subaltern voices. Communication Methods and Measures, 12(4), 239-259. doi:10.1080/19312458.2018.1453057

Dubrow, J. K. (2008). How can we account for intersectionality in quantitative analysis of survey data? Empirical illustration for Central and Eastern Europe. ASK. Research \& Methods, (17), 85-100.

Edbauer Rice, J. (2008). The new "new": Making a case for critical affect studies. Quarterly Journal of Speech, 94(2), 200-212. doi:10.1080/00335630801975434

Else-Quest, N. M., \& Hyde, J. S. (2016). Intersectionality in quantitative psychological research: II. Methods and techniques. Psychology of Women Quarterly, 40(3), 319-336. doi: doi.org/10.1177/0361684316647953

Fink, E. J., \& Gantz, W. (1996). A content analysis of three mass communication research traditions: Social science, interpretive studies, and critical analysis. Journalism \& Mass Communication Quarterly, 73(1), 114-134. doi:10.1177/107769909607300111 
Figueroa-Caballero, A., Mastro, D., \& Stamps, D. (2019). An examination of the effects of mediated intragroup and intergroup interactions among Latino/a characters. Communication Quarterly, 67(3), 271-290. doi:10.1080/01463373.2019.1573745.

Fuchs, C., \& Mosco, V. (2015). Marx and the political economy of the media. Boston, MA: Brill.

Garnett, B. R., Masyn, K. E., Austin, S. B., Miller, M., Williams, D. R., \& Viswanath, K. (2014). The intersectionality of discrimination attributes and bullying among youth: An applied latent class analysis. Journal of Youth and Adolescence, 43, 1225-1239. doi: 10.1007/s10964-013-0073-8

Goff, P. A., \& Kahn, K. B. (2013). How psychological science impedes intersectional thinking. $\mathrm{Du}$ Bois Review: Social Science Research on Race, 10(2), 365-384. doi: 10.1017/S1742058X13000313

Goodley, D. (2013). Dis/entangling critical disability studies. Disability \& Society, 28(5), 631-644. doi:10.1080/09687599.2012.717884

Grue, J. (2016). The problem with inspiration porn: A tentative definition and a provisional critique. Disability \& Society, 31(6), 838-849. doi : 10.1080/09687599.2016.1205473

Hall, S. (1980). Encoding/decoding. In S. Hall, D. Hobson, A. Lowe, \& P. Willis (Eds.), Culture, media, language. London: Unwin Hyman.

Haridakis, P., \& Hanson, G. (2009). Social interaction and co-viewing with YouTube: Blending mass communication reception and social connection. Journal of Broadcasting \& Electronic Media, 53(2), 317-335. doi:10.1080/08838150902908270

Henrich, J., Heine, S. J., \& Norenzayan, A. (2010). The weirdest people in the world?. Behavioral and Brain Sciences, 33(2-3), 61-83. doi:10.1017/S0140525X0999152X.

Hitlin, S., Scott Brown, J., \& Elder, G. H., Jr. (2006). Racial self-categorization in adolescence: Multiracial development and social pathways. Child Development, 77(5), 1298-1308. doi: doi.org/10.1111/j.1467-8624.2006.00935.x

Jin, D. Y. (2006). Cultural politics in Korea's contemporary films under neoliberal globalization. Media, Culture \& Society, 28(1), 5-23. https://doi.org/10.1177/0163443706059274

Jenkins, H., \& Deuze, M. (2008). Convergence culture. Convergence: The International Journal of Research into New Media Technologies, 14(1), 5-12. doi:10.1177/13548565 07084415

Joseph, R. (2017). What's the difference with "difference"? Equity, communication, and the politics of difference. International Journal of Communication, 11, 3306-3326.

Katz, E., Blumler, J. G., \& Gurevitch, M. (1973). Uses and gratifications research. Public Opinion Quarterly, 37(4), 509-523.

Kim, J., Seo, M., Yu, H., \& Neuendorf, K. (2014). Cultural differences in preference for entertainment messages that induce mixed responses of joy and sorrow. Human Communication Research, 40(4), 530-552. doi:10.1111/hcre.12037

Kopacz, M., \& Lee Lawton, B. (2011). The YouTube Indian: Portrayals of native Americans on a viral video site. New Media \& Society, 13(2), 330-349. doi : 10.1177/146144 4810373532

Lee, C. J., \& Niederdeppe, J. (2011). Genre-specific cultivation effects: Lagged associations between overall TV viewing, local TV news viewing, and fatalistic beliefs about cancer prevention. Communication Research, 38(6), 731-753.

Martinez, A., \& Ramasubramanian, S. (2015). Latino audiences, racial/ethnic identification, and responses to stereotypical comedy. Mass Communication and Society, 18(2), 209-229. doi:10.1080/15205436.2014.907427. 
Mastro, D. (2019). Virtual theme collection: Immigrants as minorities in the media. Journalism \& Mass Communication Quarterly, 96(1), 31-36. doi:10.1177/1077699018824402

McLaren, L. (2017). A space for critical quantitative public health research? Critical Public Health, 27(4), 391-393. doi:10.1080/09581596.2017.1326214

McGuire, W. J. (2004). A perspectivist approach to theory construction. Personality and Social Psychology Review, 8(2), 173-182. doi:10.1207/s15327957pspr0802_11

Meyrowitz, J. (2008). Power, pleasure, patterns: Intersecting narratives of media influence. Journal of Communication, 58(4), 641-663. doi:10.1111/j.1460-2466.2008.00406.x

Milan, S., \& Van Der Velden, L. (2016). The alternative epistemologies of data activism. Digital Culture \& Society, 2(2), 57-74.

Morah, D. N., \& Omojola, O. (2018). Social media use and entrepreneurship development in Nigeria: Lagos and Onitsha in focus. International Journal of Advance Study and Research Work, 1(5), 15-26. doi:10.5281/zenodo.1420101

Morgan, D. L. (2007). Paradigms lost and pragmatism regained: Methodological implications of combining qualitative and quantitative methods. Journal of Mixed Methods Research, 1(1), 48-76. doi:10.1177/2345678906292462

Mumby, D. K. (2013). Organizational communication: A critical approach. Thousand Oaks, CA: Sage Publications.

Neville, H. A., Lilly, R. L., Duran, G., Lee, R. M., \& Browne, L. (2000). Construction and initial validation of the color-blind racial attitudes scale (CoBRAS). Journal of Counseling Psychology, 47(1), 59. doi:10.1037/0022-0167.47.1.59

Oh, D. C. (2018). Racist propaganda: Discursive negotiations on Youtube of perceived anti-white racism in south Korea. Atlantic Journal of Communication, 26(5), 306-317. doi:10.1080/15456870.2018.1517767

Oliver, M. B. (1996). Influences of authoritarianism and portrayals of race on Caucasian viewers' responses to reality-based crime dramas. Communication Reports, 9(2), 141-150.

Oliver, M. B. (2002). Individual differences in media effects. In J. Bryant \& \& D. Zillmann (Eds.), Media effects: Advances in theory and research (pp. 507-524). Lawrence Erlbaum Associates Publishers.

Oliver, M. B., \& Raney, A. A. (2011). Entertainment as pleasurable and meaningful: Identifying hedonic and eudaimonic motivations for entertainment consumption. Journal of Communication, 61(5), 984-1004. https://doi.org/10.1111/j.1460-2466.2011.01585.x

Pavarala, V. (2003). Building solidarities: A case of community radio in Jharkhand. Economic and Political Weekly, 2188-2197. Retrieved from https://www.jstor.org/stable/4413632

Popper, K. (2005). The logic of scientific discovery. London: Routledge.

Ramasubramanian, S. (2016). Racial/ethnic identity, community-oriented media initiatives, and transmedia storytelling. The Information Society, 32(5), 333-342. doi: 10.1080/01972243.2016.1212618

Ramasubramanian, S., \& Oliver, M. B. (2007). Activating and suppressing hostile and benevolent racism: Evidence for comparative stereotyping. Media Psychology, 9(3), 623-646.

Ramasubramanian, S., Winfield, A., \& Riewestahl, E. (in press). Positive stereotypes and counter-stereotypes: Examining their effects on prejudice reduction and favorable intergroup relations. In A. Billings \& \& S. Parrott (Eds.), Media stereotypes: From Ageism to Xenophobia. Peter Lang Publishers. 
Remedios, J. D., \& Snyder, S. H. (2018). Intersectional oppression: Multiple stigmatized identities and perceptions of invisibility, discrimination, and stereotyping. Journal of Social Issues, 74(2), 265-281. doi:10.1111/josi.12268

Rodríguez, C. (2011). Citizens' media against armed conflict: Disrupting violence in Colombia. MN, Minneapolis: University of Minnesota Press.

Rodríguez, C., Ferron, B., \& Shamas, K. (2014). Four challenges in the field of alternative, radical and citizens' media research. Media, Culture \& Society, 36(2), 150-166. doi: $10.1177 / 0163443714523877$

Rubin, A. M. (2009). Uses-and-gratifications perspective on media effects. In J. Bryant \& M. B. Oliver (Eds.), Media effects (pp. 181-200). New York, NY: Routledge.

Said, E. (1978). Orientalism. New York: Pantheon Books.

Saleem, M., \& Ramasubramanian, S. (2019). Muslim Americans' identity management strategies in response to media stereotypes and discrimination. Media Psychology, 22(3), 373-393. doi:10.1080/15213269.2017.1302345

Scheepers, D., \& Ellemers, N. (2019). Social identity theory. In K. Sassenbert \& \& M. L.W. Vliek (Eds.), Social psychology in action: Evidence-based interventions from theory to practice (pp. 129-143). New York: Springer.

Shome, R., \& Hegde, R. S. (2002). Postcolonial approaches to communication: Charting the terrain, engaging the intersections. Communication Theory, 12(3), 249-270. doi: 10.1111/j.1468-2885.2002.tb00269.x

Soliz, J., \& Phillips, K. E. (2018). Toward a more expansive understanding of family communication: Considerations for inclusion of ethnic-racial and global diversity. Journal of Family Communication, 18(1), 5-12. doi:10.1080/15267431.2017.1399890

Splichal, S., \& Mance, B. (2018). Paradigm(s) lost? Islands of critical media research in communication journals. Journal of Communication, 68(2), 399-414. doi:10.1093/joc/jqx018

Stage, F. K., \& Wells, R. S. (2014). Critical quantitative inquiry in context. New directions for institutional Research, 2013(158), 1-7. doi:10.1002/ir.20041

Sturm, C., \& Amer, H. (2013). The effects of (social) media on revolutions-perspectives from Egypt and the Arab Spring. In International Conference on Human-Computer Interaction (pp. 352-358). Berlin, Heidelberg: Springer. doi:10.1007/978-3-642-39265-8_39.

Tajfel, H., \& Turner, J. C. (1979). An integrative theory of intergroup conflict. In W. G. Austin, \& S. Worchel (Eds), The Social Psychology of Intergroup Relations (pp. 7-24). Wiley-Blackwell.

Tal-Or, N., \& Tsfati, Y. (2015). Does the co-viewing of sexual material affect rape myth acceptance? The role of the co-viewer's reactions and gender. Communication Research, 45(4), 577-602. doi:10.1177/0093650215595073

Taylor-Clark, K., Koh, H., \& Viswanath, K. (2007). Perceptions of environmental health risks and communication barriers among low-SEP and racial/ethnic minority communities. Journal of Health Care for the Poor and Underserved, 18, 165-183. 10.1353/hpu. 2007.0113.

Trepte, S., \& Loy, L. S. (2017). Social identity theory and self-categorization theory. In P. Rössler, C. A. Hoffner, \& L. Zoonen (Eds.), The international encyclopedia of media effects. doi:10.1002/9781118783764.wbieme0088

Turner, J. C., \& Reynolds, K. J. (2011). Self-categorization theory. Handbook of Theories in Social Psychology, 2(1), 399-417. 
Valkenburg, P. M., \& Peter, J. (2013). The differential susceptibility to media effects model. Journal of Communication, 63(2), 221-243. doi:10.1111/jcom.12024

Vickery, J. (2017). Worried about the wrong things: Youth, risk, and opportunity in the digital world. Cambridge; London: MIT Press.

Wabwire, J. (2013). The role of community radio in development of the rural poor. New Media and Mass Communication, 10, 40-47. 